\title{
MORAL RESPONSIBILITY FOR NATURAL DISASTERS
}

\author{
VILIUS DRANSEIKA
}

\begin{abstract}
My aim in this paper is to explore the idea of human moral responsibility for (the outcomes) of natural disasters. First, I discuss the claim that there is often a human causal contribution to negative outcomes of even such paradigmatic natural disasters as earthquakes, typhoons, and volcano eruptions. Second, I attempt to move away from discussions attributing human causal responsibility to discussions attributing human moral responsibility for such outcomes (and to the obstacles to such attributions). I suggest that in most (perhaps even all) cases of moral responsibility for the outcomes of natural disasters moral responsibility is grounded in culpable negligence, including culpable failure to prevent the side-effects of our actions or omissions.
\end{abstract}

Key words: natural disasters; moral responsibility; causality; disaster bioethics.

\section{Introduction}

Most of the current work on applying moral theories to disasters focuses on analysing moral responsibilities in dealing with (the outcomes of) disasters. This set of issues covers ethical problems of disaster relief, research during disasters, issues of resource allocation and many other issues that are sometimes summarized under the heading Disaster Bioethics (Annas, 2010; O’Mathúna et al., 2014; Mallia, 2015). In the present paper, however, I attempt to shed some light on a different set of issues: moral responsibility for (the outcomes of) disasters. Can human agents ever be justifiably held morally responsible for the outcomes of natural disasters? And if so, what is the nature of such responsibility ascriptions and why are they important?

One may be tempted to immediately answer in the negative. The very notion of a natural disaster seems to suggest that natural disasters are "natural" precisely because they are not man-made. Furthermore, most of the public, especially in the West, no longer interpret natural disasters as justified responses by supernatural powers to human wickedness-the causes and process by which natural disasters unfold seem to be put firmly outside the moral order. "Since Lisbon [earthquake of 1755], natural evils no longer have any seemly relation to moral evils, hence they no longer have meaning at all. Natural disaster is the object of attempts at prediction and control, not of interpretation" writes Susan Neiman in her book Evil in Modern Thought (2004, p. 250) where she also notes that explanations

DE GRUYTER

(C) Institute for Research in Social Communication, Slovak Academy of Sciences 
for natural disasters formulated in terms of God's purposes are now "generally confined to fundamentalist sects and hapless victims" (ibid., p. 249).

While I do not wish to revive supernatural explanations for natural disasters, especially explanations that put blame on the victims of those disasters, I do, however, wish, in this article, to elucidate a different sense in which current thinking about natural disasters is once again deeply intertwined with questions of moral responsibility. My argument proceeds in two steps. First, I point to the limitations of a strict distinction between natural and manmade disasters - often there is a human causal contribution to negative outcomes of even such paradigmatic natural disasters as are earthquakes, typhoons, and volcano eruptions. Crucially, such potential for causal contribution by human agents is becoming widely known and recognized. Second, I attempt to move away from attributions of human causal responsibility to discussions of attributing human moral responsibility for such outcomes (and to the obstacles to such attributions).

\section{Causal responsibility for the outcomes of natural disasters}

Although natural disasters are no longer understood, at least by most of the public, as justified responses by supernatural powers to human wickedness, natural disasters can still be seen as belonging to the domain of morality, albeit in a different sense. Not as divine punishments for human misdeeds, but as something that at least sometimes can be aggravated or alleviated by human choices. Once it becomes recognized that humans may be in a position to exert influence on the outcomes of at least some natural disasters, a space opens up for the moral evaluation of the actions of those involved.

Jean-Jacques Rousseau, in his letter to Voltaire of 18 August, 1756, in which he discussed Voltaire's "Poem on the Lisbon Disaster", wrote the following:

[I]t was hardly nature who assembled there twenty-thousand houses of six or seven stories. If the residents of this large city had been more evenly dispersed and less densely housed, the losses would have been fewer or perhaps none at all. Everyone would have fled at the first shock, and would have been seen two days later, twenty leagues away and as happy as if nothing had happened. [..] For me, I see everywhere that the misfortunes nature imposes upon us are much less cruel than those that we please to add (Rousseau, 1756).

This remark is interesting in at least two ways. First, it blurs the distinction between natural and man-made disasters: the negative outcomes of natural events are in part, perhaps a crucial part, caused by earlier human actions. The architectural design, the quality of the buildings, the behaviour during the earthquake are all part of a complex causal chain that, according to Rousseau, resulted in the extreme devastation of Lisbon. The fact that this chain of events was triggered by a purely natural cause is not the whole story; as far as outcomes are concerned, it may not even be the most important part of the story. Second, this remark stresses the social aspects of disaster and thereby foreshadows current notions of resilience in a disaster context. The two ideas-causality and social resilience-are related: to be resilient is, among other things, to be able to soften the outcomes of disaster, either by setting safeguards in the initial conditions or by shaping the causal processes of the disaster as they unfold. 
There are several definitions of resilience but perhaps the most widely cited and employed is the one by the Organisation for Economic Co-operation and Development: "Resilience is [...] the ability of individuals, communities and states and their institutions to absorb and recover from shocks, whilst positively adapting and transforming their structures and means for living in the face of long-term changes and uncertainty" (2013). Discussions of resilience often focus on comparisons of two natural events that as natural phenomena share similar properties. These two events are then contrasted by showing the drastic differences in their outcomes in terms of death toll and property damage (Ten Have, 2014, pp. 18-19). One widely discussed example was a comparison of the Haiti and New Zealand earthquakes of 2010. These two events shared significant similarities in terms of the power of the earthquake and their epicentres being in the vicinity of major population centres but had very different outcomes in terms of deaths: at least 100,000 people died in Haiti and nobody died in New Zealand. At least part of the explanation for this difference is attributed to different levels of disaster preparedness and resilience. "The same level of severe shaking would cause 10 to 30 people to die per million residents in California, but 1,000 maybe more in Nepal, and up to 10,000 in parts of Pakistan, India, Iran and China", said seismologist David Wald, interviewed for a recent newspaper article on the Nepal earthquake (Borenstein, 2015).

Resilience (and, of course, its opposite-vulnerability) comes in two flavours. On the one hand, we can talk about the ability or lack of ability to forecast natural threats and plan actions accordingly in the face of these threats. This is often very difficult. For example, an important element in the disaster at the Fukushima nuclear plant in Japan in 2011 was the fact that the cooling systems servicing the reactors were disabled by the tsunami wave. When the systems were installed, engineers had little reason to expect that tidal waves could be so high. In other situations, for example in forecasting typhoon trajectories and strength, the current state of knowledge can often mean that forecasts are issued early enough and precisely enough to plan evacuation and, although perhaps not much can be done to prevent material damage, the number of human victims can often be lowered substantially.

The second type of resilience is related to human activities that have the propensity to increase or decrease the likelihood or potential extent of a disaster. For example, landslides become more likely if deforestation occurs on slopes in mountainous areas, while poorly designed and maintained dams can increase the likelihood of devastating floods, and overgrazing may lead to desertification and increase the likelihood and severity of droughts. Reforesting or artificially strengthening the slopes may, conversely, decrease the likelihood of landslides. This type of resilience also includes psychological or community resilience, understood as the capacity of individuals and communities to cope with the impact of the disaster.

Both types of resilience challenge the distinction between natural and man-made disasters. Even in the first case, granted the distinction made between natural processes and human reactions to those processes based on scientific forecasts, the outcomes of disasters depend on both these two factors. It is even clearer in the second case. Of course, in some situations the extent and nature of the potential catastrophe may be such that in current conditions it would be impossible to build resilience (in either of the two senses): for example, in the case of the imminent impact of a massive asteroid. Nonetheless, in many of the cases traditionally treated as natural disasters, people, communities or states can exert an influence on both types of resilience. 
So what kinds of human causal contribution can be identified in natural disasters? One way to make the distinction is by showing that human activities can either be triggering causes of disaster or they can be structuring causes that shape the process leading to the outcomes of the disaster. This distinction is borrowed from Fred Dretske (2004). Cases of natural disasters caused by human trigger alone are perhaps rare, not least because they pose a conceptual issue: it may be awkward to call such situations natural disasters. However, examples can be found. It is very likely that the Sidoarjo mud flow-a mud volcano in eruption since 2006 in Indonesia-was triggered by drilling for natural gas. Forest fires can be triggered by bonfires that were left without being properly extinguished. There may also be more indirect, perhaps probabilistic, human influences on natural events. Examples may be found in forecasts by the Intergovernmental Panel on Climate Change that climate change induced by human activity will lead to more frequent extreme weather events or claims by the Red Cross in their World Disaster Report that human-induced climate change will result in more frequent droughts, floods or malaria outbreaks.

Structuring causes include a set of initial conditions in which the disaster unfolds; some of these conditions will be natural, some man-made. For example, the high-rise buildings in Lisbon, mentioned by Rousseau, were a part of the complex of conditions that shaped the outcomes of the earthquake.

Sometimes the same set of human activities can be both triggering and structuring causes: imagine the deforestation of a slope that both increases the probability of a landslide being triggered and the degree of severity.

In addition to causation by action it is important to mention causation by omission. Sometimes normative expectations can shape the normative context within which omissions and failures are seen as being causally efficient (see Haldane, 2011; Williams, 1995). As noted by Asscher (2008), omissions become something a person can be blamed for only in the context of "surrounding responsibility". Sometimes it can be appropriate to say that negative outcomes were caused in part by early-warning systems not working as they should, by relevant officials not organizing evacuation or not taking preventive steps of resiliencebuilding.

For the purposes of this paper, it is important to note that there is increasing recognition and knowledge of aspects of the human causal influences on the processes involved in natural disasters. We have increasingly more scientific information on disaster risks, early-warning systems are becoming more effective and more widespread, and also the public in at least some parts of the world are becoming more perceptive to the potential of human-caused environmental degradation and climate change increasing the likelihood or scale of a disaster.

\section{Moral responsibility for the outcomes of natural disasters}

There is a long tradition in philosophy of distinguishing between human evil and natural evil. Human evil is traditionally understood to be suffering that results from human activity, while natural evil occurs without direct human involvement. Historically, some of the most frequently discussed examples of natural evil have been natural disasters, such as the 1755 Lisbon earthquake. Current thinking has it, however, that this distinction, as applied to natural disasters, is deeply problematic. Natural disasters are complex events that are 
triggered and shaped by a set of both natural and man-made causes and initial conditions. The previous section discussed some of the reasons for treating the distinction with care.

The traditional distinction between natural evil and human evil is related to (but is not equivalent to) another traditional distinction between natural evil and moral evil. Human participation in causal processes that lead to natural disasters having negative outcomes does not necessarily mean that we deal with the human moral responsibility for the negative consequences of these processes. For example, if a hurricane wind tosses me into someone who is thereby hurt, I am clearly a part of the causal chain leading to this suffering. Yet, typically I will not be held morally responsible for the suffering.

In other situations we can justifiably be held or hold someone else responsible and culpable for the outcomes of a natural disaster. Yet, we never (or almost never) encounter paradigmatic cases of moral responsibility in the context of natural disasters. That is, if by paradigmatic cases we mean planned actions that are based on the intention to cause the disaster or aggravate its consequences. Most (perhaps all) cases of moral responsibility for the outcomes of natural disasters are either cases of culpable negligence or cases of responsibility for the unintended or unforeseen side-effects of our actions or omissions.

In some cases the context provides us with salient normative expectations that can ground ascriptions of responsibility. Perhaps the simplest examples are situations in which an official did not perform her professional duties (or did not perform those duties in a way that can be reasonably expected) and thereby contributed to the negative outcomes of the disaster. Perhaps someone failed to perform routine-checks of early warning systems and the systems did not sound the alarm when the disaster struck. Or perhaps the officials responsible for evacuating the disaster zone failed to perform their task. In such situations we can base our ascriptions of moral responsibility on our ascriptions of culpable negligence, where the latter is defined in the context of professional duties or contractual obligations.

This reasoning can be extended to contexts where other types of normative expectations are salient. Many of us, for example, are aware of the fact that carbon emissions lead to human-induced global warming which in turn can increase the likelihood and severity of some types of disasters. We come to accept that such an increase in the likelihood and severity of disasters is a bad thing, and this results in a normative expectation on our part to lower our carbon footprint. Acting (or failing to act) in conflict with this normative expectation can then begin to be moralized. Here, the outcomes for which we are evaluated are likely to be side-effects of our other intentional behaviours, such as heating our homes or travelling to work. The knowledge condition is very important for this type of moral responsibility ascription. At least in some societies there now is an expectation that one should be aware of basic claims about the human contribution to climate change. Failure to possess this knowledge is beginning to be treated as culpability (e.g. Seibokaite, 2015). These normative considerations provide the "surrounding responsibility" within which it becomes possible to ascribe moral responsibility for the predictable side-effects of our actions and omissions. In a similar way, normative expectations can also arise from realizing that the current means of dealing with disasters sometimes favours privileged populations, creating additional disadvantages for already vulnerable populations. One such widely discussed issue is the fact that the floodwalls in lower Mississippi tend to be built in a way that directs floodwater away from the more affluent areas (Steinberg, 2006). The more we learn about 
the side-effects of human activities, the more likely we are to encounter situations in which we can be expected to take these side-effects into account when acting.

\section{Concluding remarks}

If the considerations provided in this paper have some merit, we can conclude that sometimes human beings can be morally responsible for the outcomes of natural disasters and such responsibility ascriptions will most often be grounded in culpable negligence, including the culpable failure to prevent the side-effects of our actions or omissions. However, even if we come to accept that human beings can sometimes be morally responsible for the outcomes of natural disasters, in individual cases it can be very difficult to establish firm causal and conceptual links between human activities (either actions or omissions) and the outcomes of natural disasters. First, as already mentioned, human activities often constitute only a part of the causal process leading to the outcomes. Second, relevant human activities are often collective actions in which the contribution of a particular individual is very small-individual action is extremely unlikely to tip the scales (consider the contribution to global warming) (Banks, 2013; Gilbert, 2006; Sinnott-Armstrong, 2010). Third, where the probability of a natural disaster occurring is sufficiently low, post hoc arguments to the effect that particular human agents had positive obligations to take preventive steps in order to mitigate the outcomes of the disaster cannot be easily produced. Fourth, the unpredictable and catastrophic nature of natural disasters makes it extremely difficult for an agent to foresee the potential outcomes of her activities. All these considerations suggest that it can be difficult to ascribe responsibility in individual cases. They do not show, however, that we can never be justified in doing this.

Normative expectations presuppose that the agent is in a position to know or predict the consequences of her actions. This information may often be unavailable to the agent. Nonetheless, science-backed information on disaster risks and disaster resilience is becoming more readily available (including via influential reports by such international bodies as the IPCC or UNISDR) and societal expectations that we should seek and act on this information are becoming more widespread. These expectations are currently even beginning to have large-scale societal effects. For example, partly in response to public pressure, university endowments, pension funds and various foundations have started shifting their capital out of greenhouse gas emission-intensive activities. The more prognostic power we gain, the greater our technological abilities to prevent or alleviate disasters, or deal with the outcomes of disasters. The more we know about the effects of human activities on processes occurring on Earth, the more difficult it is to hide behind our ignorance.

\section{Acknowledgments}

This paper resulted from my discussions with participants of COST Action IS1201 Disaster Bioethics. I would like to thank Dónal P. O'Mathúna, the participants of a workshop at Prešov University as well as two reviewers at Human Affairs for their insightful comments on an earlier manuscript. Funding for the workshop on moral theories and disasters at the University of Prešov, Slovakia (13-15 May 2015) and open-access publication was provided by COST Action IS1201 (http://DisasterBioethics.eu). 


\section{References}

Annas, G. J. (2010). Worst case bioethics: Death, disaster, and public health. Oxford: Oxford University Press.

Asscher, J. (2008). The moral distinction between killing and letting die in medical cases. Bioethics, 22(5), 278-285.

Banks, M. (2013). Individual responsibility for climate change. The Southern Journal of Philosophy, 51(1), 42-66.

Borenstein, S. (2015). Experts gathered in Nepal a week ago to ready for earthquake. Available online: http://www.salon.com/2015/04/25/experts_gathered_in_nepal_a_week_ago_to_ready_for_ earthquake/

Dretske, F. (2004). Psychological vs. biological explanations of behavior. Behavior and Philosophy, 32,167-177.

Gilbert, M. (2006). Who's to blame? Collective moral responsibility and its implications for group members. Midwest Studies in Philosophy, 30(1), 94-114.

Haldane, J. (2011). Identifying privative causes. Analysis, 71(4), 611-619.

Mallia, P. (2015). Towards an ethical theory in disaster situations. Medicine, Health Care and Philosophy 18(1), 3-11.

Neiman, S. (2004). Evil in modern thought: An alternative history of philosophy. Princeton: Princeton University Press.

O’Mathúna, D. P., Gordijn, B., \& Clarke, M. (Eds.). (2014). Disaster bioethics: Normative issues when nothing is normal. Dordrecht: Springer.

Organisation for Economic Co-operation and Development (2013). What does "Resilience" Mean for Donors? An OECD Factsheet. Available online at: http://www.oecd.org/dac/May\%2010\%202013\% 20FINAL\%20resilience\%20PDF.pdf

Rousseau, J.-J. (1756). Rousseau to Voltaire, 18 August 1756, from J.A. Leigh, (Ed.), Correspondence complète de Jean Jacques Rousseau, vol. 4 (Geneva, 1967), pp. 37-50; (Translated by R. Spang). Available online at: http://www.indiana.edu/ enltnmt/texts/JJR\%20letter.html

Seibokaite, A. (2015). Climate change as a 'hard' case of collective responsibility. In D. Kissane \& A. Volacu (Eds.), Modern dilemmas: Understanding collective action in the 21st Century (pp. 117142). Stutgart: ibidem-Verlag.

Sinnott-Armstrong, W. (2010). It's not my fault: Global warming and individual moral obligations. In S. M. Gardiner et al. (Eds.), Climate Ethics: Essential Readings (pp. 332-346). Oxford: Oxford University Press.

Steinberg, T. (2006). Acts of God: The unnatural history of natural disaster in America. Oxford: Oxford University Press.

Ten Have, H. (2014). Macro-triage in disaster planning. In D. P. O’Mathúna, B. Gordijn, \& M. Clarke (Eds.), Disaster bioethics: Normative issues when nothing is normal (pp.13-32). Dordrecht: Springer.

Williams, B. (1995). Acts and omissions, doing and not doing. In B. Williams Making sense of humanity and other philosophical papers (pp. 349-360). Cambridge: Cambridge University Press.

Department of Logic and History of Philosophy,

Faculty of Philosophy,

Vilnius University,

Universiteto Str. 9,

Vilnius 01513,

Lithuania

E-mail: vilius.dranseika@fsf.vu.lt 